\title{
Review: $\beta$-agonists plus ipratropium bromide improve airflow obstruction in adults with acute asthma
}

Stoodley $R G$, Aaron SD, Dales RE. The role of ipratropium bromide in the emergency management of acute asthma exacerbation: a metaanalysis of randomized clinical trials. Ann Emerg Med 1999 Jul;34:8-18.

QUESTION: Is the addition of inhaled ipratropium bromide to $\beta$-agonist therapy effective in the emergency treatment of adults with acute asthma?

\section{Data sources}

Studies were identified by searching Medline (1966 to January 1997), EMBASE/Excerpta Medica (1980-97), CINAHL (1982 to 1997), Biological Abstracts on CD (1990 to 1997), the Cochrane Library, Current Contents (1996 to August 1997), and bibliographies of relevant papers and by contacting the manufacturer of ipratropium.

\section{Study selection}

Published and unpublished studies in English, French, and Italian were selected if they were randomised, placebo-controlled trials that assessed the use of ipratropium in addition to $\beta$-agonists (administered by inhaler or wet nebuliser) compared with $\beta$-agonist therapy alone in adult patients with acute asthma presenting to a hospital emergency department (ED) or similar acute care setting. Exclusion criteria were patients $<18$ years old or studies of patients who had chronic obstructive pulmonary disease alone.

\section{Data extraction}

Trial design and methodological quality; drug treatments, dosages, and time intervals; patient characteristics; mean percentage change from baseline in $\mathrm{FEV}_{1}$ or peak expiratory flow rate (PEFR); hospitalisation rate; and adverse effects.

\section{Main results}

10 studies (1377 patients, age range 30-53 y) met the selection criteria. Meta-analysis showed a greater improvement with $\beta$-agonists plus ipratropium bromide than with $\beta$-agonists alone: improvement in $\mathrm{FEV}_{1}$ was $7.3 \%$ (95\% CI $3.8 \%$ to $10.9 \%$ ), or $100 \mathrm{ml}$ (CI 50 to $149 \mathrm{ml}$ ), at assessment times ranging between 45 and 90 minutes (5 studies); improvement in PEFR was $22.1 \%$ (CI $11.0 \%$ to $33.2 \%$ ), or $32 \mathrm{l} / \mathrm{min}$ (CI 16 to 47 $\mathrm{l} / \mathrm{min}$ ), at assessment times ranging between 30 and 60 minutes (5 studies). In 3 studies (1064 patients), $\beta$-agonists plus ipratropium bromide reduced the rate of admission to hospital $\{11 \% \text { v } 15 \%, \mathrm{p}=0.04\}^{*}$ more than $\beta$-agonists alone. Neither combination therapy nor monotherapy was associated with adverse effects.

\section{Conclusion}

Ipratropium bromide added to $\beta$-agonist therapy improves airflow obstruction better than $\beta$-agonists alone in the emergency treatment of adults with acute asthma.

*Data provided by author.

\section{COMMENTARY}

In the United States, 2 million ED visits for acute asthma occur annually, ${ }^{1}$ and the healthcare costs associated with this disease are enormous. ${ }^{2}$ Guidelines for acute asthma care have been developed, and treatments that improve outcomes in patients with acute asthma are an important contribution to health care.

Treatment involves the early use of inhaled $\beta_{2}$-agonists. Systemic corticosteroid therapy is also recommended early in ED care. ${ }^{3}$ Both of these treatments are consistently used in North American EDs. However, the use of anticholinergic agents, such as ipratropium bromide, is rather limited. This reflects, in part, conflicting evidence in the published literature regarding efficacy.

By reducing the biases common to systematic reviews, Stoodley and colleagues have provided high-quality evidence that shows a beneficial effect of adding ipratropium bromide to inhaled $\beta_{2}$-agonists in adult patients with acute asthma. Using accepted methods, the reviewers have shown improvements in pulmonary function; the effect appears greatest in patients with more severe asthma. Although the clinical significance of these effects is debated in the review, it would be considered important in cases of severe airway obstruction. Moreover, the evidence suggests that ipratropium bromide is beneficial in reducing the hospitalisation rate. In summary, although questions still need to be resolved about ipratropium bromide therapy in the ED setting (such as the dose-response relation), it seems prudent to use this agent in combination with $\beta_{2}$-agonists for patients with severe acute asthma to improve pulmonary function and reduce admissions to hospital.

Brian H Rowe, MD, MSc

University of Alberta Edmonton, Alberta, Canada

1 Camargo CA Jr, Richardson LD. Epidemiology of asthma. In: Brenner BE, editor. Emergency asthma. New York: Marcel Dekker, 1999:80.

2 Weiss KB, Gergen PJ, Hodgson TA. An economic evaluation of asthma in the United States. N Engl J Med 1992;326:862-6.

3 Rowe BH, Keller JL, Oxman AD. Effectiveness of steroid therapy in acute exacerbations of asthma: a meta-analysis. Am J Emerg Med 1992;10:301-10. 